\title{
Processos tradutórios na pesquisa em educação: o Projeto Escrileituras
}

Máximo Daniel Lamela Adól

Sandra Mara Corazza'

Maria Idalina Krause de Campos

\section{Resumo}

Este artigo articula algumas ações tradutórias com as atividades de pesquisa, ensino e extensão do Projeto Escrileituras: um modo de ler-escrever em meio à vida, vinculado ao Programa Observatório da Educação Capes/Inep. Aborda a produção de dados realizada via instrumentos elaborados especificamente para dar a ler certa concretude que há daquilo que resultou das vivências do projeto e suas ações. Apresenta modos de confrontar esses dados com aquilo que se pode extrair do não quantificável e, talvez, pouco ou dificilmente classificável no âmbito das atividades propostas e executadas na pesquisa. Esse confrontamento exigiu uma ampliação, não apenas da perspectiva de análise, mas do modo de extração dos dados. Nesse sentido, o texto delibera que o projeto se constituiu na contramão de uma ordem de sistematização, ao não definir por antecipação um problema por meio de um método hipotético-dedutivo, para a pesquisa que se propôs. Mas optou pela divergência inclusiva como um modo de evidenciar o caráter dramático do pensamento educacional no campo da didática e do currículo, provocando que a coleta e análise de dados da pesquisa associada ao projeto se dobre em novas produções; assim fazendo se cria uma zona de contágio em que os encontros, fortuitos ou forçados, derivam em inequívocas mutações das matérias que pelo projeto circulam.

\section{Palavras-chave}

Escrileituras - Tradução - Educação - Pesquisa. 


\title{
Translating processes in research in Education: Writing- Reading Project
}

Máximo Daniel Lamela Adól

Sandra Mara Corazza'

Maria Idalina Krause de Campos'

\begin{abstract}
This paper articulates some translating actions and research, teaching and extension activities of the project known as Escrileituras (Writing-Reading): A way of reading-writing in life, which is linked to Capes/Inep Observatory of Education Program. It approaches data production through instruments specifically designed to give concreteness to what has resulted from both the experiences in the Project and its actions. The paper presents ways of confronting such data with what can be extracted from the non-quantifiable an, perhap, the little or hardly classifiable in the sphere of the activities proposed and performed in the research. Such confrontation has required widening not only the analysis perspective but alsothow data were extracted. In this sense, the paper considers that the Project did not follow a systematization order, as a problem was not previously defined by means of a deductive-hypothetical method for the research proposed. Rather, it chose inclusive divergence as a way to evidence the dramatic character of the educational thought in the field of didactics and curriculum, thus causing data collection and analysis associated with the Project to be unfolded in new productions; by doing so, a zone of contagion has been created, in which the encounters, either fortuitous or forced, have resulted in unequivocal mutations of the matters circulating in the Project.
\end{abstract}

\section{Keywords}

Writing-Reading - Translation - Education - Research. 


\section{Introdução}

Este artigo visa articular algumas ações tradutórias com as atividades de pesquisa, ensino e extensão, ou seja, entre as várias atuações realizadas durante quatro anos no Projeto Escrileituras: um modo de ler-escrever em meio à vida (Projeto Escrileituras), vinculado ao Programa Observatório da Educação Capes/ Inep. A execução desse projeto se deu em atravessamento com outros projetos de pesquisa que o subsidiaram e que dele são derivados.

0 artigo aborda a produção de dados particulares produzidos por essas pesquisas. Desse modo, o que apresentamos a seguir trata de informar que, ao referir dados de pesquisa, estamos, na verdade, referindo-nos à repercussão produzida via instrumentos elaborados, especificamente, para dar a ler certa concretude que há daquilo que resultou das vivências dos projetos e suas ações.

Entendemos os dados como informações que coletamos, ou produzimos, de modo a quantificar e qualificar por meio de classificações como modos de estancar variações de pensamento. No entanto, o que nos interessa e delineia nossa dificuldade é confrontar esses dados com aquilo que se pode extrair do não quantificável e, talvez, pouco ou dificilmente classificável no âmbito das atividades propostas e executadas nas pesquisas. Esse confrontamento exige uma ampliação não apenas da perspectiva de análise, mas do modo de extração dos dados à maneira de extrair um tom [mood; Stimmung] do que é produzido.

Como podemos ler em Varela (2003), entre as décadas de 1950 e 1970, as pesquisas no campo das ciências humanas e sociais acreditavam que o conhecimento poderia se basear nos modelos computacionais via manipulação simbólica. Acreditava-se que por meio de regras do tipo lógico, via modelos sistêmicos da informática, lidar-se-ia com a tradução de um tipo de linguagem natural, procurando igualar a prática da pesquisa e o desenvolvimento de conhecimento à inteligência de um perito altamente treinado. Ambicionou-se, com tal tradução, resolver problemas gerais sobre o conhecimento e, deste modo, lidar também com questões centrais da cognição. Contudo, no decorrer das tentativas generalizadoras de tais processos percebeu-se que:

As tarefas mais comuns, mesmo as executadas por insetos minúsculos, são simplesmente impossiveis de realizar com uma estratégia computacional. Esses anos de pesquisa resultaram na compreensão, pelos envolvidos, de que é necessário inverter as posições do perito e da criança na escala de desempenho. Ficou claro que a forma de inteligência mais profunda e fundamental é a de um bebê, que adquire a linguagem a partir de emissões vocais diárias e dispersas e delineia objetos significativos a partir de um mundo não especificado previamente. (VARELA, 2003, p. 73).

A partir dessa constatação, houve uma virada nas pesquisas sobre o conhecimento e o foco passou a revitalizar uma relação com o que Varela (2003) chama de presente imediato e concreto. Tal relação busca concentrar a atenção da pesquisa em atividades que ocorrem em um espaço específico, que ele denomina de junções do presente imediato, pois, no dizer de Varela:

[...] é no presente imediato que de fato o concreto vive" (2003, p. 73), talvez seja nessa junção do presente imediato que viva o tom de uma produção carregada de “informação estética (BENSE apud CAMPOS, 2013a, p. 02).

O Projeto Escrileituras se constituiu tendo em perspectiva esse presente imediato, no qual o concreto vive. Recorremos à proposição de Varela (2003) mesmo sabendo que não se trata de um autor presente tanto no projeto, como em seus desenvolvimentos, pois, interessamnos suas proposições como argumento e perspectiva para tratar as repercussões das 
ações da pesquisa e, desse modo, compor essa perspectiva com a de um plano de imanência e empirismo transcendental deleuzianos e uma teoria da tradução haroldiana.

A par disso, o Projeto Escrileituras surgiu como um espaço em que as relações com as linguagens pudessem ser tomadas por meio de certas emissões dispersas que delineassem sentidos, a partir, não de um mundo previamente especificado, mas de elementos que constituíam a especificação de um mundo pela inserção de modos conceituais e operatórios de fazê-los surgir. Isso, que aqui chamamos mundo, trata-se de um multiverso de possibilidades de atuação que constituiu o projeto como uma multiplicidade de presentes imediatos e concretos em permanente devir; ou seja, chamamos mundo a construção de um espaço operacionalizado pelas linguagens.

No entanto, esse multiverso ou mundo de possibilidades tampouco é dado. 0 que temos dele são novas dispersões sobre o vivido e vivível. Assim, o artigo procura constituir certa concretude alienada dos dados, mas paradoxalmente indiciada com eles, e que por meio deles delineia uma espécie de repertório ausente, o qual, no entanto, se faz presente como força da materialidade da escritura repercutida da pesquisa.

Dessa forma, o artigo: a) apresenta traços gerais do Projeto Escrileituras; b) argumenta a proposição do projeto de atuar por meio de oficinas de transcriação e escrileituras, associando essa escolha a noções de didática e currículo operadas no projeto; c) apresenta os instrumentos de geração de dados; d) relaciona o presente imediato como um lugar em que o concreto convive com o empirismo transcendental deleuziano e a teoria da tradução haroldiana; e) apresenta uma dinâmica operatória inventiva para o tratamento dos dados; f) conclui afirmando a continuidade da pesquisa.

\section{Sobre o Projeto Escrileituras}

0 projeto "Escrileituras: um modo de ler-escrever em meio à vida" esteve vinculado ao Programa Observatório da Educação Capes/ Inep, desenvolvido entre 2011 e 2015. 0 mesmo tratou de compor oficinas de transcriação e escrileituras no campo da educação, procurando operar, entre outros desdobramentos, com as unidades analíticas de AICE (autor, infantil, currículo e educador), tal como esboçado pela pesquisadora e coordenadora geral do projeto (CORAZZA, 2012b; CORAZZA et al., 2014c). A necessidade de criar tais unidades analíticas se deu para permitir, em meio à atuação empírica do mesmo, olhar para o presente imediato e concreto das oficinas cruzando elementos conceituais reportados por tais unidades.

Essa operação se configurou mediante uma possibilidade combinatória e correlacional de lidar com as unidades expressas por AICE, alinhavando a possibilidade de balizar a direção do trabalho educacional de ensinar, escrever, orientar, pesquisar e ocupar espaços, fazer imagens e confrontar signos, expressos na unidade EIS (espaços, imagens e signos) (CORAZZA, 2014a). Ou seja, combinar e correlacionar EIS com AICE (espaços, imagens e signos a autor, infantil, currículo, educador) e, nesse processo combinatório e correlacional, operacionalizado primeiramente por meio de texto, colocar-se diante da presença que tal combinatória provoca como pensamento sobre ensinar, escrever, orientar, pesquisar. Em suma, falar sobre certa economia que pode haver na composição material dessas articulações para a educação.

Tal procedimento exploratórioexperimental de pesquisa tem como intuito criar meios para a produção de ações de pensamento que avizinhe aquelas e aqueles que a ela se vinculem por meio da pesquisa em educação a um estado de humor, ou mood, contido nas criações das artes, ciências e filosofia em interface com a educação. Essa ação voltada para um exercício analítico da pesquisa e ofertada por meio de oficinas,

Busca alternativas para a compreensão e a superação dos índices apontados pelo INEP, especialmente no que se refere às dificuldades 
de aquisição e utilização da linguagem nas escolas, expressas pela maioria dos estudantes da educação básica, por meio da Prova Brasil. Essas dificuldades encontramse ligadas ao próprio uso e produção da linguagem. Enquanto relacionados ao conjunto formado por conteúdos escolares e operações mentais, que envolvem: leitura, escrita e interpretação; variações contínuas de temas e imagens; singularizações de leituras e raridades de escritura; processos de pensamento, formas de conteúdos e de expressão; relações espaciais, temporais e históricas; sensibilidade para as artes como modos de criação; habilidades e competências de formular e desenvolver problemas, em ciências humanas, sociais, exatas e assim por diante. (CORAZZA et al., 2014c, p. 1031).

Assim, as oficinas de transcriação operadas no projeto Escrileituras procuraram considerar - em suas proposições e em suas possíveis repercussões - processos de criação nos campos das artes, ciências e filosofia, para extrair dos mesmos modos de expressare produzir em educação. Tais oficinas foram desenvolvidas durante os quatro anos que compreenderam a pesquisa do Projeto Escrileituras e aconteceram no âmbito de desenvolvimento de ensino, pesquisa e extensão de quatro instituições de ensino superior vinculadas ao projeto, a saber: UFRGS, UFPel, UFMT e Unioeste.

Foram registradas um total de 570 oficinas desenvolvidas pelo projeto e, pode-se afirmar que boa parte delas não chegou a desdobrar sua produção alinhada tanto à conceitografia que as nomeou de oficinas de transcriação e tampouco às balizas teórico-conceituais que poderiam ser tomadas das unidades analíticas. No entanto, tal intuito fez produzir outros modos de lidar com a inserção de ações de pesquisa na educação básica e fundamental, além de correlacionar, via os vínculos entre professores das redes de ensino municipais, estaduais e federais, pesquisas de mestrado acadêmico, de doutorado e pós-doutorado, assim como outras pesquisas vinculadas e em colaboração.

\section{As oficinas, a didática e o currículo}

Nas oficinas, o foco foi dado aos possíveis movimentos de pensamento, às experimentações de forças que atravessam a escrita e a leitura e que vivem em ações carregadas de acasos e situações inusitadas. Desse modo, o espaço curricular foi envolvido na afırmação de uma transversalidade com as artes, a filosofia e as ciências, tomando para si a tarefa de compor um currículo como uma construção aberta e, por esse movimento, fazer do conhecimento uma composição multidimensional e, portanto, potente.

A escolha por oficinas se deu para dar ênfase a um espaço de construção, curricular e didática, variável. Desse modo, as experimentações das oficinas do Projeto Escrileituras são tomadas de um currículo em constante metamorfose. Considera-se, assim, que o conhecimento não se funda em bases de objetividade estanque, e que o conhecer possui uma arquitetura composta de diversos tipos de saberes e de valores em transformação. Desse modo, o projeto optou por afirmar um currículo mutante, provocando, com isso, que sua didática também o fosse.

Assim fazendo, acredita-se que, por meio desse currículo instável, contornou-se certa incumbência que coloca o currículo a serviço de uma institucionalização homogeneizante ao selecionar determinados saberes que acabam servindo somente como reprodução que interrompe a produção de singularidades.

0 currículo e a didática elaborados por meio de oficinas interessaram-se por saberes que multipliquem concepções de mundo, fazendo dessa multiplicação uma mutiplicidade de mundos possíveis.

0 que o projeto almejou com os movimentos de pensamento exercitados nas oficinas foi um olhar segundo o qual o conhecimento servisse como mola propulsora 
para a criação tanto de si como de novos mundos expressos por outras linguagens, diferindo de uma noção baseada na representação e na separação entre sujeito e objeto como marca prévia para o processo do conhecimento. Para tanto, essa escolha valeu-se da ideia de que

[...] o pensar depende mais de um processo do que do objeto considerado; mais de um método de criação do que de resultados; mais de experimentações do que da aplicação de teoria à prática; mais de problematizações do que de descobertas. (CORAZZA, 2012, p. 14b).

Note-se que é posto em movimento um método informe; a interrogação e a variação estão presentes em todo o processo, fazendo com que as regras não sejam fixas e rígidas. 0 método do informe é o de capturas de forças dos textos, das imagens, das musicalidades, de tudo que devém em vida potente entre fluxos de pensamentos. Assim, esse método produz ficção, ou seja, "os pesquisadores capturam forças imaginárias, fantasísticas e intelectuais, que os conduzem ao trabalho criador" (CORAZZA, 2012, p. 19), operando no campo educacional.

As oficinas procuraram uma didática e um currículo que causasse estranheza e desconforto ao propor o inabitual, ao ocupar outros mundos diversos dos já conhecidos nas escolas e salas de aula, para que, pela forma de expressão (didática) e forma de conteúdo (currículo), os participantes, junto aos ofıcineiros, pudessem traçar possibilidades de deliberar outras formas de habitar esses espaços ou, talvez, de recriá-los.

Para Varela, no contexto da lida cotidiana, passamos por microcolapsos, que afetam o corpo e o espírito numa "torrente de transições de micromundos recorrentes” (2003, p. 77); e é nessas situações que "apresentamos uma prontidão-para-ação” (2003, p. 76) que pode colocar-nos diante de algo concreto e específico. Varela apresenta o seguinte exemplo:
Imagine-se caminhando pela rua, talvez indo ao encontro de alguém. 0 dia está acabando e não há nada muito especial em sua mente. Você se sente relaxado, naquele estado que podemos chamar de "prontidão" do pedestre que está simplesmente dando uma caminhada. Você põe a mão no bolso e de repente descobre que sua carteira não está lá como de costume. Colapso: você pára, seu aparelho mental obscurece, sua tonalidade emocional muda. Antes que você se dê conta, surge um novo mundo: você percebe claramente que deixou sua carteira na loja onde acabou de comprar cigarros. Sua disposição agora muda para uma preocupação acerca de perder documentos e dinheiro, sua prontidãopara-ação é agora a de voltar rapidamente para a loja. Você presta pouca atenção para as árvores e os transeuntes à sua volta; toda a sua atenção concentra-se em evitar maiores atrasos. (VARELA, 2003, p. 76).

Dito de outra forma, as abstrações geradas em nossas mudanças de tonalidade emocional não são invalidadas, elas servem como combustível para ações corporificadas e colocam em ação a criatividade da cognição que vai estabelecendo seus pequenos domínios, nos quais o conhecimento de novos micromundos vai sendo descoberto.

De certa forma, é como Valéry alude à sua produção de escrita ao dizer: "Tenho a estranha e perigosa mania de querer, em qualquer matéria, começar pelo começo, o que vem a dar em recomeçar, em refazer uma estrada completa, como se tantos outros já não a houvessem traçado e percorrido" (VALÉRY, 2011, p. 210). Pois o verdadeiro estado poético do espírito, segundo ele, ocorre na vida que nos espanta, nos graus de forças de seus acidentes. São ciclos que se estabelecem. 0 estado poético que requer, por vezes, o isolamento. Convêm estimar um tempo próprio para que um poema surja por meio de microcolapsos do pensamento. Em outros casos, há uma aproximação brusca de 
ideias que se apoderam de nosso corpo e, como caçadores atentos, adentramos nessa floresta de ideias com todos os músculos orientados para a caça. Esse incidente necessariamente não produz um poema, mas incorpora-se ao pensamento e, assim, uma proposição qualquer pode surgir, servindo de instrumento para uma pesquisa posterior.

Com efeito, não se trata de fazer um currículo dimensionado somente pela experiência do aluno, pois, como diz Michael Young (2015), quando se trata de uma educação que também se preocupa em gerar e possibilitar uma nova produção de conhecimento em localidades e lares desfavorecidos, a escola e a participação ativa na escola pode ser a única oportunidade de adquirirem um conhecimento poderoso, que Young distingue do conhecimento dos poderosos. Trata-se de se ocupar em perceber na produção do currículo como ele pode incorporar conhecimento, uma vontade de poder de viés nitzscheano, que torne os estudantes - que dele se valem poderosos, no sentido de que possam constituir um mundo ao conseguir traduzi-lo ao campo de suas forças. Contrariando um modo de estar subjugado pelas pressões de um mundo do qual pouco acessam de modo analítico, criador e crítico, mas que interfere verticalmente no modo como estes o habitam.

Um apreender que toma o conhecimento como uma linha de conexão com o fazer de um currículo que, a sua vez, incorpora as ações - de um sentido prático da lida cotidiana - à construção de uma restituição identitária que não convoca uma identidade restituída em individualismos, mas, pelo contrário, advoga por uma subjetivação política, singular e coletiva. Um currículo que dê atenção aos microcolapsos do presente imediato e concreto fornecendo coordenadas para o pensamento criador e, por isso, crítico e que se experimenta num empirismo transcendental em que "a ideia não é o elemento do saber, mas de um 'aprender' infinito" (DELEUZE, 1988, p. 310). Nessa proposição, o valor está agregado ao espírito das forças que do pensamento se apossam e, por isso, são capazes de produzir novas imagens que passam a enunciar e novamente atualizar pensamentos.

Opondo-se à mera técnica, o currículo proposto pelo Projeto Escrileituras procurou se valer mais dos meios do que dos fins e, nesse entre-lugar, acreditou que o acesso dado ao conhecimento pode se tornar invenção que problematiza relações múltiplas, pois se trata de inventar um vivível.

A cada vez, faz-se necessário dar conta da importância das discussões curriculares no contexto nacional, por sua diversidade continental - mas também sua relação para um além-fronteiras -, um olhar para as naturezas ímpares presentes nos espaços da educação. Com atenção para suas especificidades, arriscar o desenho de um currículo que possa ser sempre outro e à procura de contornar homogeneizações de saberes.

\section{Instrumentos de geração de dados}

No sentido de avaliar, ou melhor, de dar a ler essas produções das ações de pesquisa expressas pelas oficinas, foram desenvolvidos pela coordenação geral do projeto instrumentos de geração de dados com o intuito de abordar de modo crítico-genealógico e experimentalexploratório não somente as oficinas, mas também outras atividades desenvolvidas nesses quatro anos de pesquisa. Vale ressaltar que esses instrumentos, configurados aqui como exercícios de autoanálise, autoobservação e autoavaliação, se compõem dentre os objetivos de pesquisa de um Projeto de Pesquisa PQ CNPq, que tem como uma de suas metas avaliar as produções de pesquisa em educação realizadas pelo Projeto Escrileituras, com o intuito de - numa dobra sobre as mesmas - observar suas produções e processos para com isso complementar, correlacionar e consolidar a formação de professores-pesquisadores, assim como os resultados e impactos das produções. 
A seguir destacamos os instrumentos que servem para o tratamento dos dados por eles produzidos, quais sejam:

1) Chave de Escrileitura para Pesquisar o Currículo do Projeto Escrileituras (Método de Dramatização); 2) Roteiro para Inventariar Procedimentos Didáticos de Tradução em uma Aula ou Oficina; 3) Ficha de EIS AICE; 4) Drama na Comédia Intelectual Espiritográfica de EIS AICE; 5) estudar, ler, escrever e fazer aparecer o que foi pensado e praticado em relação às "13 Unidades Temáticas", que compuseram o Projeto Escrileituras: 1. AICE (AutorInfantil-Currículo-Educador); 2. Aula; 3. Biografema; 4. Criação; 5. Crítica Genética; 6. Currículo; 7. Didática; 8. Dramatização; 9. EIS (Espaços, Imagens, Signos); 10. Escrileituras; 11. Método; 12. Tradução; 13. Transcriação. (CORAZZA, 2014b, p. 23).

Tais instrumentos não podem ser entendidos no intuito de produção de resultados de pesquisa confiáveis, pois não foram formulados de modo a constituir e avaliar situações de validação ou invalidação de resultados. 0 rigor pelo qual esta pesquisa se pautou não antecipa um modo de verificar os resultados pela definição de variáveis que possam ser alocadas em uma dimensão de interrelação causal, no sentido em que alguns valores, estipulados por essas variáveis, sejam determinados como causas e outros como efeitos.

Em presença dessa apresentação de instrumentos de geração de dados, o projeto recebeu como retorno algumas produções que deles se utilizaram. Diante dos instrumentos que retornaram, desdobramos uma nova produção que nos permite contrapor e re-produzir uma analítica baseada na interação aleatória gerada no encontro e incidência temática das produções. Essa nova produção procura contornar uma analítica de quantificação dos mesmos, pois considera que tabular quantitativamente as incidências das treze unidades temáticas seria tarefa inerte ou apenas coadjuvante de uma ação significativa; sendo que a pesquisa se interessa em um para além da significação, ao poder contornar as interpretações, e verter certa concretude do estado de humor das produções e não suas tematizações.

0 que essa extração nos permite é, mais que quantificar, criar possibilidades de observar relações - materializadas nas conexões sintáticas e semânticas produzidas pelas conjunções das unidades temáticas por meio da construção textual - entre as unidades analíticas e o que foi produzido a partir dos instrumentos de geração de dados das oficinas.

Desse modo, fizemos uma tabulação na qual destacamos um cruzamento entre unidades temáticas e unidades analíticas e operatórias. Essa tabulação nos ajuda a delinear outro modo de ler conexões, ou melhor, de produzir sistemas que provoquem encontros heterogêneos, mas não implica resultados. Assim, podemos afirmar que sabemos como provocar os encontros, mas não sabemos o que neles ocorre. Há algo sempre misterioso; no entanto, não há mistério e tampouco falta de rigor na atribuição de valores e na simetria das proposições que geram tais encontros. Levando em consideração, com Norbert Elias e John Scotson, que "sem o uso das palavras como instrumentos de pesquisa, os números ficam mudos" (2000, p. 59), cruzamos as relações entre números e palavras, propondo que, com os números, dinamizemos uma métrica com certa simetria e rigor; no entanto, vemos neles uma poética que nos deixa tomar a afirmação acima e dizer que, sem os números as palavras ficariam turvas, agitando os espíritos e destinando-os a uma repetitiva instabilidade da atenção.

\section{Da pesquisa mediante a transcriação em educação}

A transcriação é lida como uma operação de tradução criadora e crítica (CAMPOS, 2013c, p. 77). Entende-se, com Paz (2009), que aprender a falar é aprender a traduzir e que não há tradução que não seja uma operação 
literária, e, com Paul Valéry (1956), que escrever é um trabalho de tradução desde que nesse ato haja reflexão, no sentido de colocar o próprio pensamento em uma dobra especular em que o mesmo possa se perceber em processo. Tratase de conceber a escrita, em especial aquela vinculada a um ato de criação, como a evidência de um processo de tradução permanente e, nesse sentido, como exercício de pensamento. Em educação, esse exercício compactua com aquele que nos foi legado pelo pensamento freireano, ou seja, admite e opera uma ruptura com os esquemas verticais relacionados às ações voltadas ao conhecimento. Pensamento que age na afırmação de que "os homens se educam em comunhão, mediatizados pelo mundo" (FREIRE, 2012, p. 76). No entanto, esse mundo não é dado, esse mundo está sempre lido com a linguagem que o concebe.

0 Projeto Escrileituras talvez procure evidenciar o que a literatura elaborada como metaficção, desde Cervantes (2004), tornou tema e meio de sua prática. Ou seja, uma escritura que ratifica o seu processo como literatura ao demonstrá-lo desse modo. Tratase de colocar à mostra o processo de construção e criação, evidenciando-o. Nesse caso, o que se procura evidenciar é o que se cria e como se cria em educação, na medida em que a mesma lida com linguagens e, em especial, põe sua prática em evidência via linguagem escrita. 0 termo escrileituras toma de empréstimo a recursividade, corroborada pela teoria literária e filosofia, de que não há leitura que não seja ela mesma um processo de escritura e viceversa ou, como disse Paulo Freire (2011), que não há dicotomização entre leitura e escrita.

Talvez seja um modo de afirmar que a ficção é a nossa mais profunda realidade. Pois falar em realidade é falar em ficção e metaficção e, desse modo, afırmar que o que chamamos de real se trata de uma permuta com o ficcional. Poderíamos dizer que a produção de realidade funciona como a ação de uma ficção da ficção que ativa materialmente um real de experiência inventiva.
No entanto, não se trata de rejeitar o referente ou de afirmá-lo como realidade extralinguística, fazendo de toda linguagem representação. Considera-se que o itinerário de uma ruptura com a mediação representacional é o da participação da linguagem como constituinte e constituidora desse real. $\mathrm{Na}$ representação, é necessário que algo preencha o lugar de uma identificação. Com esse ato - o da identificação - ocorre, necessariamente, um distanciamento daquilo que foi identificado, uma vez que toda identificação só é possível pela classificação e categorização de elementos previamente classificados, ou seja, conhecidos. Para identificar é necessário reconhecer o que se identifica por meio daquilo que o diferencia ou o iguala, num rol de classificações, e as classificações não são o real, mas modos de lidar com a constituição de realidades.

Nesse sentido, uma escrita e, consequentemente, um pensamento que atua na ordem metaficcional coloca essa ação - a da própria escrita e sua classificação - em uma complexa forma que envolve uma multiplicidade de componentes de sentido. Procura desdobrar o processo de produção de sentido que há na experiência produzida pelas linguagens. Essa escritura, que se elabora como metaficção, admite que não fala de um real, mas é ela mesma a participação ativa de um real que faz da leitura uma escuta, por vezes silenciosa, mas produtiva. Escrever, nesse caso, é traduzir, na medida em que a escrita se comporta como uma ação poética da leitura que se materializa como realidade de escritura e de produção de sentidos.

Por meio dessas considerações, perscrutar a tradução como transcriação - no sentido de tradução poética -, no campo da educação, torna-se um exercício de observação de nossas práticas cotidianas como professores e professores lidando com conteúdos, currículos, didáticas e suas repercussões. Trata-se de criar maneiras para que se constitua uma observação - materializável e materializada em escrita entre outras produções - de como se cria uma relação de afecção com o que se conhece e, 
especialmente, como se pode abrir o campo de produção com e para aquilo que difere: o desconhecido.

Podemos afirmar, com James Wood (2012, p. 63), que a literatura é, evidentemente, diferente da vida, uma vez que a vida é cheia de detalhes,

[...] mas de maneira amorfa, e raramente ela nos conduz a eles [...]. A literatura nos ensina a notar melhor a vida; praticamos isso na vida, o que nos faz, por sua vez, ler melhor o detalhe na literatura, o que, por sua vez, nos faz ler melhor a vida.

É importante ressaltar que, ao falar em literatura, não estamos falando da instituição literária, ou seja, tratando de muitos dos componentes que envolvem essa prática que denominamos de literatura, como suas classificações em gêneros, cânones, sua economia, promoções e festas, institucionalizações de nomes de autores etc. 0 que nos interessa é tratar da escritura ao modo dito literário, ou melhor, "a questão da linguagem pensada como o âmago do ato literário" (MACHAD0, 2000, p. 12).

Com isso, escolhemos fazer pesquisa em educação acompanhados de algumas produções literárias que, a sua vez, estão alimentadas pelas filosofias e teorias que ambientaram suas produções e leituras. Nesse sentido, interessa-nos evocar e perscrutar procedimentos e processos tradutórios em educação. Procura-se, com eles, modos de ler e dar a ver as nossas próprias produções educacionais de didáticas, currículos e práticas de ensino no âmbito de nossas atividades como professoras e professores.

\section{Um modo de produzir dados no Projeto Escrileituras}

No decorrer da pesquisa, com o intuito de observar e desenvolver processos tradutórios em educação, ou seja, dispositivos que desencadeiem práticas que se desdobram em atividades de ensino e pesquisa, desenvolvemos uma investigação que, com vistas na transcriação haroldiana, pudesse adentrar e produzir modos de pensar o espaço, as imagens e a produção de textos para e no cotidiano educacional. Procuramos, desse modo, criar maneiras de avaliar e desenvolver pesquisa em educação fora dos preceitos que excluem a complexidade e a dinâmica dessas produções, ao classificá-las por meio de predefinições estanques, ou que prescrevem uma leitura recognitiva, ou seja, do já conhecido. Com isso, nos forçamos a contornar uma tradição em pesquisa que trabalha por meio de análises de sequências lógicas, caracterizando fases, avaliando resultados como consequências e como relações de causa e efeito. Uma vez que, para nosso entendimento e o da pesquisa que nos propomos, sistematizar desse modo os dados de um campo é agir como se este não fosse instável e para além de possibilidades demarcáveis.

A política educacional se apresenta como metaestável, recebe influências e influencia para além dos lindes de suas pobres demarcações. A comunidade que constitui a política educacional é cada vez mais diversa (BALL, 2011); nesse sentido, pensar as práticas docentes e a pesquisa sem separar o modo de atuar de seu pensamento constitui operar com a teoria no sentido de dar a ver uma prática que se inventa a cada vez e a cada fluxo produtivo.

0 espaço da invenção é aquele que constitui uma possibilidade enquanto possibilidade de invenção; desse modo, é interessante perceber que não se pode identificar uma invenção, pois uma vez identificada ela se torna material de descoberta, ou seja, algo que incide no que já existe (CORAZZA, 2013a).

Nesse entremeio da pesquisa, valemonos das produções literárias para, com elas, operar no sentido de tomá-las como procedimento de apropriação e organização de uma matéria de escrita que, a sua vez, se valida como pensamento para a educação, pois é em aula, em nossas pesquisas e em modos de ler possibilidades para a educação que essas 
produções nos importam como dramatizações; é em aula, na sua prática e inventividade exigida da docência que a criação literária suporta essa dramatização docente. Nesse sentido, foram desenvolvidos alguns textos e materiais utilizados em aula, ambicionando tratar, correlacional e combinatoriamente, unidades de EIS e AICE em escrileituras.

Com as produções de Georges Perec e seus trabalhos com literatura combinatória e potencial julgamos que podemos operar, por meio de uma transcriação de suas práticas literárias para a educação, de modo a obter outras possibilidades de avaliar, listando e inventariando o material produzido no Projeto Escrileituras: um modo de ler-escrever em meio à vida; no Projeto Dramatização do infantil na comédia do intelecto: método Valéry-Deleuze e adotando as metas e objetivos estabelecidos no Projeto Didática da Tradução, Transcriação do Currículo: Escrileituras da Diferença.

Essas outras possibilidades de avaliar se juntam à necessidade de traçar modos que ultrapassem uma analítica do classificável - sem deixar de se valer da classificação e da análise - para pesquisar em ciências humanas e sociais e, consequentemente, em educação. No entanto, o interesse está na observação do classificável como um movimento de leitura e não como o padrão de observação de uma verdade, admitindo o caos mesmo nas classificações e nos modelos observáveis e observados.

Trata-se de dar atenção, como foi observado na organização coordenada por Wallerstein (1996), à necessidade de abrir a pesquisa em ciências humanas e sociais observando a funcionalidade, se é que ela existe, da validade das linhas de demarcação que separam a atividade intelectual e de investigação da grande área, assim como a concepção de ciência que se tem evocado em suas institucionalizações.

A classificação das ciências sociais foi erigida em redor de duas antinomias que deixaram de concitar o vasto apoio de que já desfrutaram: a antinomia entre passado e presente, e a antinomia entre disciplinas idiográficas e nomotéticas. Há uma terceira antinomia entre mundo civilizado e mundo bárbaro, que, embora contando já com poucos defensores públicos, na prática ainda habita as mentalidades de muitos estudiosos e investigadores. (WALLERSTEIN, 1996, p. 135).

Abrir as ciências humanas e sociais - a educação incluída nessa grande área - significa atuar para além "dos debates intelectuais em torno da lógica das atuais divisões disciplinares" (WALLERSTEIN, 1996, p. 135) e seus vários problemas relacionados a recursos e modos de uma possível institucionalização de práticas transdisciplinares e transversais. Significa adotar modos de análise e perspectivação das pesquisas, didáticas e currículos que procurem a dissolução de antinomias como as apresentadas acima, ou melhor, uma tentativa anti-ilusória que as coloque em jogo de maneira a suprimir seus efeitos perversos.

Com isso, visamos assumir um desdobramento que convida a transcriar e observar processos tradutórios em educação, incorporando uma nova pergunta como meta e objetivo estabelecido para a atuação na pesquisa do Projeto Didática da Tradução, Transcriação do Currículo: Escrileituras da Diferença, qual seja: diante das produções realizadas nos quatro anos dos Projetos Escrileituras e Dramatização do Infantil na Comédia do Intelecto: Método ValéryDeleuze, como podemos, com elas, dar a ver suas singularidades produtivas, avaliar seus resultados como experimentações de pensamento, estimar suas potências, classificar alguns de seus códigos e modos de operar conceitos sem com isso reduzir essa tarefa a uma sistematização que empobreça o viés das próprias produções e tampouco superestime suas materialidades?

Desse modo, atuamos para pensar uma didática e um currículo da tradução, voltados para as próprias produções e seus desdobramentos. 


\section{Do tratamento inventivo dos dados}

Para tratar os dados - no sentido de dar a ler novas produções deles derivadas -, mais que interpretar os instrumentos ou definir suas leituras, constituímos um rol de dez unidades analíticas e operatórias, classificadas a partir dessas produções, e decidimos trabalhar com dez das treze unidades temáticas acima apresentadas e produzidas para os instrumentos de geração de dados. No entanto, essa classificação em unidades analíticas e operatórias se configura como instrumento para colocar em marcha uma dinâmica que desestabiliza as unidades como classificações estanques, na medida em que as mesmas ganham validade somente quando tomadas pelo movimento gerado, a partir de uma relação combinatória e correlacional, proporcionada por algoritmos, isto é, são os encontros que as fazem vivas, ou melhor, é o que há entre uma e outra do processo relacional que atualiza a vitalidade de seus encontros.

Essa escolha se deu para conformar um quadrado latino de dez por dez que possibilitasse operar com os dados da pesquisa por meio de um jogo combinatório, gerado por uma sequência algorítmica que se assume como apropriação dos procedimentos criadores de A vida modo de usar, de Georges Perec (2009). Cria-se, assim, uma maneira própria para lidar com os dados da pesquisa por meio de uma composição de transposição poiética dos encontros entre as unidades temáticas de EIS AICE e as unidades analíticas e operatórias tomadas da leitura dos instrumentos de pesquisa e das produções por eles geradas. Foram 21 produções (OLINI, 2015) que retornaram geradas pelo instrumento de pesquisa denominado Chave de Escrileitura para Pesquisar um Currículo: Método de Dramatização (CORAZZA, 2013b), todas elaboradas pelos pesquisadores associados aos quatro núcleos vinculados ao projeto.

Desse modo, a ação de pesquisar ocorre por meio da utilização de uma composição combinatória e de um processo algorítmico que resulta na construção de novos textos compostos com essas matérias e a partir dessas matérias, configurando um trabalho de crítica. Paz (2009) define a crítica como uma tarefa que faz da leitura um ponto de partida para um novo texto. 0 encontro dos dados de pesquisa classificados entre unidades temáticas e unidades analíticas e operatórias atuam como dobras de uma nova produção, permitindo-nos contrapor e reproduzir uma analítica baseada na interação aleatória gerada no encontro e na incidência temática dos textos.

Permite-se, com esse tratamento, criar possibilidades de ressaltar uma relação entre as unidades analíticas e o que foi produzido, a partir dos instrumentos de geração de dados e das ofıcinas, fazendo com que essa relação seja ativada de modo materializado nas conexões sintáticas e semânticas produzidas pelas conjunções das unidades temáticas e unidades analíticas e operatórias por meio de nova construção textual.

Como indicamos acima, tomamos o processo de construção combinatória e algorítmica do procedimento criativo de Georges Perec, ao escrever A vida modo de usar (2009), e dispomos os dados da pesquisa do seguinte modo: a) um quadrado latino de matriz ortogonal de ordem dez por dez, ou seja, um quadrado formado por cem quadrados menores. Essa composição se faz no entrecruzamento das dez colunas com as dez linhas, compondo assim cem casas. A cada uma dessas casas foi atribuído um valor, dos quais dez unidades temáticas são dispostas nas linhas e dez unidades analíticas e operatórias, extraídas dos instrumentos de pesquisa, dispostas nas colunas. Desse modo, compomos vinte indicadores sendo que cada casa está dividida em quatro, respondendo pelo recorte de dois temas relacionados ao currículo e outros dois à didática; b) utilizamos uma razão da numerologia do sistema pitagórico, ou seja, reduzimos por adição todos os números a apenas um entre um e nove. Assim, as letras do alfabeto latino foram convertidas em números seguindo uma sequência. Desse modo, as letras 
que compõem as unidades analíticas EIS AICE formaram a sequência numérica 5911935 que, reduzida por adição, resultou no número seis. Esse processo serviu para discernir o ponto de partida do algoritmo no quadrado latino, ou seja, a coordenada de partida deu como início o ponto de encontro entre a coluna seis e a linha seis; c) devido ao resultado da razão numerológica de EIS AICE para o ponto de partida, utilizamos na primeira versão combinatória, coincidentemente, a mesma sequência algorítmica utilizada por Perec (2009) em A vida modo de usar, associada ao movimento do polígrafo do cavalo no jogo de xadrez, fazendo, desse modo, que se recorram todas as casas do quadrado latino sem repetir nenhuma; d) igualmente em A vida modo de usar, admitimos que ocorresse uma falha entre as passagens do ponto 65 ao 66 do quadrado, duplicando o movimento do polígrafo do cavalo e inserindo, com essa duplicação, uma casa vazia. Essa coincidência, dada também por nossas escolhas, nos obrigou a assumir os encontros fortuitos e, com eles, criar novas relações, associações, valores e visibilidades diante do heterogêneo. A ênfase recorre, assim, não mais à reprodução de valores preestabelecidos, mas à repetição de valores e formas que dão corpo à dramatização de um mundo como teatro.

Para doar, ao dado aleatório, significação, pesquisamos a simbologia do número seis e afirmamos, com Bachelard (2001), que este é o número associado ao ar, elemento que figura dentre os quatro que compõem os princípios materiais fundamentais da natureza na concepção dos filósofos gregos da Antiguidade Clássica, enquanto os outros três elementos são: terra, água e fogo. 0 elemento ar, a sua vez, é associado por Bachelard (2001) à ideia da imaginação dinâmica do movimento. Na composição de nosso algoritmo, quando o número seis foi duplicado, fizemos com que o movimento do polígrafo do cavalo se duplicasse dando à sequência de movimentos um erro que resulta numa falha, uma vez que, com a duplicação do movimento, a sequência não percorre mais todos os cem quadrados, mas apenas 99. Essa falha compromete o rigor de toda a regra deixando de completar o quadro. Há nela um desvio que alterou a sequência deixando uma casa de fora da composição; seus dados não serão tratados na combinatória.

Com isso, fazemos com que a prática da pesquisa em educação tenha de lidar com o imprevisível mesmo diante do previsto e possa afirmar, assim, a vitalidade dos encontros e das relações inusitadas. Com o inusitado e com a falha, também se cria. A falha já não pode ser lida como falha, mas como desvio necessário e como potência criadora.

Assim fazendo, temos nas linhas as seguintes unidades temáticas: aula, biografema, criação, crítica genética, currículo, didática, dramatização, método, tradução/transcriação e escrileituras, e, nas colunas, dez unidades analíticas e operatórias, quais sejam: novos meios de expressão; dinamismos espaçostemporais; afecções e acidentes; citações; composição de incorporais; valor que faz falar; da ciência ao sonho; conceitos e imagens de pensamento; séries em intensidades heterogêneas; sintomas de uma vontade.

Cada unidade analítica operatória se refere a uma ação, operação, procedimento, inserção, ordem, classificação, conceito/ conceituação etc., de acordo com o instrumento de pesquisa utilizado. Assim, cada uma das dez colunas solicita um tipo de recorte de leitura dos instrumentos, compondo uma restrição operatória. Desse modo, as colunas foram distribuídas pela designação acima listada, sendo que essa distribuição será variável no decorrer da pesquisa.

Das unidades analíticas e operatórias extraímos elementos dos retornos da "Chave de escrileitura para pesquisar um currículo: método de dramatização" (CORAZZA, 2013b). Desse modo, cada um dos pontos é composto por quatro elementos, resultando numa lista de quatrocentos elementos extraídos das produções. Duzentos serão relacionados a EIS 
(currículo) e duzentos relacionados a AICE (didática). 0 processo exige que tenhamos que extrair de cada retorno dos instrumentos de pesquisa quatro elementos norteados pelas unidades temáticas e unidades analíticas e operatórias, por exemplo: a primeira unidade temática é "aula" e a primeira unidade analítica e operatória é "novos meios de expressão". $\mathrm{Na}$ leitura de uma ficha, se extrai o que podemos discernir a respeito de aula e o que há ou não, nessa produção, de novos meios de expressão. Nessa combinatória, associamos dois fragmentos a EIS e dois a AICE, e teremos aí o primeiro ponto do quadrado latino completo de informações extraídas do instrumento de geração de dados.

Esse procedimento será realizado até completar o quadro. Desse modo, depois de completado o quadro - no limite de leitura ofertado pela pesquisa - aplicamos o movimento do polígrafo do cavalo, que consiste em um movimento diagonal como no jogo de xadrez, conformando um algoritmo. $\mathrm{Na}$ sequência que utilizamos, ao definir o primeiro ponto no encontro da linha seis com a coluna seis, estabelecemos, para percorrer todos os pontos sem repetir nenhum, o ponto dois no encontro entre a linha sete e coluna oito, o próximo ficou entre a linha seis e a coluna dez, e assim por diante.

A cada encontro o pesquisador se vê diante de elementos extraídos da pesquisa e com eles vai formando um texto carregado de imagens e signos diversos, compostos pela materialidade semântica e sintática doada pelos instrumentos de geração de dados, compondo, assim, um texto heterogêneo e limitado pela repetição, com diferença, daquilo que a pesquisa pode gerar como matéria dada à palavra.

\section{Considerações finais}

Dar a ler a construção de dados de pesquisa e seus desdobramentos é, como em um processo de tradução criadora, materializar certa equivalência na diferença (JAKOBSON,
1969). O Projeto Escrileituras se constituiu na contramão de uma ordem de sistematização, no sentido de defınir por antecipação um problema por meio de um método hipotético-dedutivo, para a pesquisa que se propôs.

$\mathrm{Na}$ formulação do currículo, como conjunto de saberes para serem tomados nas propostas e atividades de pesquisa, ensino e extensão operacionalizadas pelo projeto, optouse pela divergência inclusiva. Tal divergência foi orientada pelos rigores ofertados pelo método de dramatização deleuziano associado ao pensamento valéryano e seu legado à constituição de discursos sobre o conhecimento nas ciências, artes e filosofia. Desses encontros derivou o Método Valéry-Deleuze (CORAZZA, 2013a), também denominado Método do Informe. 0 Método Valéry-Deleuze é tomado como um modo de evidenciar o caráter dramático do pensamento educacional no campo da didática e do currículo. Nesse método o drama é tido como um processo dinâmico que coloca em cena forças e potências que muitas vezes estão encobertas na ação. Deste modo, o método coloca algumas questões, entre elas: Como surgem as formas? É possivel o surgimento do novo e a produção do informe em educação? (CORAZZA, 2013a).

Especificamente, o currículo do Projeto Escrileituras, constituído e associado ao Método Valéry-Deleuze, agiu por contato e contágio com as matérias dos currículos escolares, doando aos mesmos aspectos de uma mutação dotada de autoengendramentos. Visto que, quando uma matéria do currículo escolar se encontra com um processo de experimentação que desarticula seu lugar já significado, esta já não atua como uma posição específica e particular de poder. Pois tais experimentações fazem com que se desarticule da fixidez do significado e passe a ser tomada como um efeito de sentido. Depois disso, a matéria se dispõe em vias de fazer-se e se autoengendra em novas articulações, de modo a atualizar uma invenção recorrente de si e da realidade. Desse modo, o currículo não mais se apresenta 
como um critério de mobilização entre a escolha de alguns saberes em detrimento de outros, mas como uma zona de contágio em que os encontros, fortuitos ou forçados, derivam em inequívocas mutações das matérias curriculares; cada uma com sua força.

\section{Referências}

BACHELARD, Gaston. 0 ar e os sonhos: ensaio sobre a imaginação do movimento. Tradução de Antonio de Pádua Danesi. São Paulo: Martins Fontes, 2001.

BALL, Stephen. Política social y educacional, empresa social, hibridación y nuevas comunidades discursivas, Propuesta Educativa, Buenos Aires, v. 2, n. 36, Año 20, p. 25-34, nov. 2011.

CAMPOS, Haroldo de. Da tradução como criação e como crítica. In: TÁPIA, Marcelo; NÓBREGA, Thelma Médici (Org.). Haroldo de Campos - transcriação. São Paulo: Perspectiva, 2013a. p. 01-18.

CAMPOS, Haroldo de. Da transcriação: poética e semiótica da operação tradutora. In: TÁPIA, Marcelo; NÓBREGA, Thelma Médici (Org.). Haroldo de Campos - transcriação. São Paulo: Perspectiva, 2013c. p. 77-104.

CAMPOS, Haroldo de. Para além do princípio de sudade: a teoria benjaminiana da tradução. In: TÁPIA, Marcelo; NÓBREGA, Thelma Médici (Org.). Haroldo de Campos - transcriação. São Paulo: Perspectiva, 2013b. p. 47-59.

CERVANTES, Miguel de. Don Quijote de La Mancha. São Paulo: Real Academia Española: Alfaguara, 2004.

CORAZZA, Sandra. Chave de escrileitura para pesquisar um currículo: método de dramatização. [S. I.: s. n.], 2013b. Texto digitado. CORAZZA, Sandra Mara. Didaticário de criação: aula cheia. Porto Alegre: UFRGS, 2012b.

CORAZZA, Sandra. Dramatização do infantil na comédia intelectual do currículo: método Valéry-Deleuze. [s. L.: s. n.], 2010b. Projeto de pesquisa - bolsa de produtividade CNPq.

CORAZZA, Sandra Mara. Ensaio sobre EIS AICE: proposição e estratégia para pesquisar em educação. [S. I.: s. n.], 2014a. Texto digitado.

CORAZZA, Sandra Mara. Método Valéry-Deleuze: um drama na comédia intelectual da educação. Educação \& Realidade, Porto Alegre, v. 37, n. 3, 2012. Disponível em: <http://migre.me/rkFN7>. Acesso em: 13 jun. 2014.

CORAZZA, Sandra Mara. 0 que se transcria em educação? Porto Alegre: UFRGS: Doisa, 2013a.

CORAZZA, Sandra. Para uma filosofia do inferno na educação: Nietzsche, Deleuze e outros malditos afins. Belo Horizonte: Autêntica, 2002.

CORAZZA, Sandra Mara. Projeto didática da tradução, transcriação do currículo: escrileituras da diferença. [S. I.: s. n.], 2014b. Texto digitado.

CORAZZA, Sandra Mara et al. Escrileituras: um modo de ler-escrever em meio à vida. Educação e Pesquisa, São Paulo, v. 40, n. 4 p. 1029-1044, out./dez. 2014c.

DELEUZE, Gilles. Diferença e repetição. Traduçaõ de Luiz Orlandi e Roberto Machado. Rio de Janeiro: Graal, 1988.

ELIAS, Norbert; SCOTSON, John. Os estabelecidos e os outsiders: sociologia das relações de poder a partir de uma comunidade. Tradução de Vera Ribeiro. Rio de Janeiro: Jorge Zahar, 2000.

FREIRE, Paulo. A importância do ato de ler: em três artigos que se completam. São Paulo: Cortêz, 2011.

FREIRE, Paulo. Pedagogia do oprimido. Rio de Janeiro: Nova Fronteira, 2012. 
JAKOBSON, Roman. Aspectos linguísticos da tradução. In: JAKOBSON, Roman. Linguística e comunicação. Tradução de Izidoro Blikstein e José Paulo Paes. São Paulo: Cultrix, 1969. p. 63-72.

MACHADO, Roberto. Foucault, a filosofia e a literatura. Rio de Janeiro: Zahar, 2000.

OLINI, Polyana. Noologia do currículo do Projeto Escrileituras. Porto Alegre: [s. n.], 2015. Projeto de tese de doutorado em educação. Universidade Federal do Rio Grande do Sul.

PAZ, Octavio. Traducción: literatura y literalidade. Belo Horizonte: Fale/UFMG, 2009.

PEREC, Georges. A vida modo de usar. Traduçaõ de Ivo Barroso. São Paulo: Companhia das letras, 2009.

VALÉRY, Paul. Meu Fausto. Tradução de Lídia Fachin e Sílvia Maria Azevedo. Cotia: Ateliê, 2011.

VALÉRY, Paul. Variations sur les Bucoliques. Paris: Gallimard, 1956.

VARELA, Francisco. 0 reencantamento do concreto. In: 0 REENCANTAMENTO do concreto. São Paulo: Hucitec, 2003. p. 71-86. (Cadernos de subjetividade).

WALLERSTEIN, Immanuel et al. Para abrir as ciências sociais. São Paulo: Cortês, 1996.

WOOD, James. Como funciona a ficção. Tradução de Denise Bottmann. São Paulo: Cosac Naify, 2012.

YOUNG, Michael. Para que servem as escolas? Educação \& Sociedade, Campinas, v. 28, n. 101, p. 1287-1302, 2007. Disponível em: <http://cedes.unicamp.br>. Acesso em: 11 ago. 2015.

Recebido em: 01.10.2015

Aprovado em: 13.04.2016

Máximo Daniel Lamela Adó é professor adjunto da Faculdade de Educação da Universidade Federal do Rio Grande do Sul.

Sandra Mara Corazza é professora titular da Faculdade de Educação da Universidade Federal do Rio Grande do Sul.

Maria Idalina Krause de Campos é doutoranda em educação (Bolsista Capes), no Programa de Pós-Graduação em Educação na linha Filosofias da Diferença e Educação da Universidade Federal do Rio Grande do Sul. 